\title{
Theoretical Simulation and Experimental Study on the Crystal Morphology of L-arabinose
}

\author{
Biao $\mathrm{HU}^{1,2,3, \mathrm{a},{ }^{*} \text {, Lei LIANG }}{ }^{1,2}$, Ping-Jun ZHANG ${ }^{1,2}$, Shu-Juan YU ${ }^{3}$ \\ ${ }^{1}$ Guangdong Engineering Research\&Development Center for Comprehensive \\ Utilization of Plant Fiber \\ ${ }^{2}$ Guangdong Province Engineering Laboratory for Biomass Utilization,Guangzhou \\ 510316, China \\ ${ }^{3}$ College of Light Industry and Food Science, South China University of \\ Technology,Guangzhou, 510640, China. \\ aemail: hubiao2003@126.com \\ * Corresponding Author: Tel/Fax: +86 2084168894
}

Keywords: Crystal morphology, BFDH, Growth morphology, Equilibrium morphology, $\beta$-L-arabinose.

\begin{abstract}
The crystal morphology, growth faces as well as the structures of important facets of $\beta$-L-arabinose were simulated by BFDH, growth morphology(GM) and equilibrium morphology(EM) methods in this paper. By measuring the attachment energy and lattice energy of the crystal, the relative growth rates and morphology of the crystal is determined. Results show that the morphology of $\beta$-L-arabinose calculated by BFDH, GM and EM method is approximate rectangular parallelepiped, nearly cuboid and nearly spherical, respectively. The shape simulated by GM is consistent with the experimental crystal obtained by cooling crystallization. The $\{020\}$ is the largest among all the facets calculated. Projection of the facet showed that there exists no hydroxyl group or hydrogen atom on the $\{020\}$ facet, while some hydrogen atoms and a hydroxyl group appear on and outside the $\{101\}$ facet. Conclusion: L-arabinose morphology can be modified by changing of standing layerthickness and the relative growth rate of $\{101\}$ facet.
\end{abstract}

\section{Introduction}

Morphology is an important property of crystalline materials, which influences material properties such as bulk density, mechanical strength, agglomeration and mixing characteristics, as well as re-dissolution properties[1]. Accurate predictions on crystal morphologies before preparation can enhance the efficiency and then become more and more strongly desirable[2]. Many models have been used for morphology prediction, those models are built on the consideration of crystal structure (Bravais [3] -Friedel[4] -Donnay -Harker[5] model, BFDH), surface energies (Periodic Bond Chains theory (PBCs) [6-10], and attachment energy theory (AE) [11, 12]. Despite these advances in morphology modeling, there are still significant challenges to overcome before been widely used[13].

L-arabinose is a new functional low-caloric sugar with selective intestinal sucrase inhibition effect [14-17]. It is the critical agent in the synthesis of antiviral drug 
Clevudine[18, 19] and Telbivudine[20, 21], which is a potent anti-hepatitis B (HBV) agents. It also has great usage in tumor therapy [22-24], chemistry [25, 26], and biology field [27, 28]. L-arabinose is a colorless needle-like crystal. Duo to the fragility and difficulty in crystal-culturing, measuring of morphology by cultivating a large crystal is not so easy. In this paper, the crystal morphology and growth faces of $\beta$-L-arabinose were calculated by BFDH, growth morphology $(\mathrm{GM})$ and equilibrium morphology(EM) method of Materials Studio 6.0 (Accelry Software Inc., San Diego, USA). Results show that the predicted morphologies by BFDH and GM method are in good consistency with the $\beta$-L-arabinose crystals obtained by cooling crystallization.

\section{Theory and Computational Techniques}

The crystal shape may be described by the interplanar spacing ( $\left.d_{\mathrm{hkl}}\right)$, which is inversely proportional to the relative growth rates $\left(R_{\mathrm{hkl}}\right)$. The faces having larger $R_{\mathrm{hkl}}$ narrow or even disappear, while the faces having smaller $R_{\mathrm{hkl}}$ will gradually expand in the growth process and remain in the Crystal face finally.

The BFDH states that the morphological importance (MI) of a face is proportional to the interplanar spacing $d_{h k l}$ and the morphologically most important faces grow the slowest (Eq.1):

$$
R_{h k l} \propto d_{h k l}^{-1} \propto M I_{h k l}^{-1}
$$

The BFDH estimates the morphology from the crystal symmetry and the lattice parameters to generate a list of possible growth faces and their relative growth rates. This method ignores the chemical nature, packing of the atoms and molecules that form the crystal. Thus, it is a weak approach to predict the crystal morphology, but provides the first habit prediction approach.

The PBCs theory, proposed by Hartman and Perdok[6-8], assumes the presence of strong chemical bonds within the crystal. The underlying assumption that strong bonds form more easily and faster than that of weak bonds, and crystal growth only occurs when an uninterrupted chain of strong bonds is present within the crystal structure. The faces are categorized as flat faces, stepped faces, and kinked faces. The relationship between those faces is ( Eqs.2):

$$
\mathrm{R}_{\text {kinked }}>\mathrm{R}_{\text {stepped }}>\mathrm{R}_{\text {flat }}
$$

The PBCs considered the strength and stoichiometry of the solid-state intermolecular forces through calculation of the surface attachment energy, the energy released on the addition of a building unit to the growing crystal surface. The PBCs considerates unit cell parameters, fractional coordinates, and symmetry information of the crystal, thus obtain a crystal of more sophisticated than BFDH.

The AE explicitly includes the energetic interactions required to attach a new slice to the surface of crystal. It assumes that the $R_{h k l}$ is proportional to the attachment energy $\left(E_{a t t}\right)$ - the energy released on the attachment of a growth slice to the growing 
crystal surface (Eq.3). According to the AE theory, faces with the lowest $E_{\text {att }}$ grow the slowest, therefore has highest $M I$.

$$
\mathrm{R}_{\mathrm{hkl}} \propto \mathrm{E}_{\mathrm{att}}=\mathrm{E}_{\text {latt }}-\mathrm{E}_{\text {slice }}
$$

Where $E_{\text {latt }}$ is the lattice energy, $E_{\text {slice }}$ the energy of a $d_{h k l}$ thickness growth slice.

The AE theory assumes that the crystal surface is smooth, while in fact that surface relaxation exists in many crystals (especially inorganic crystals), indicating AE theory is only suitable for morphology prediction of organic compounds.

\section{Experiment}

\section{Crystal Chemistry of $\beta$-L-arabinose Crystal}

For the single-crystal X-ray diffraction, a sample size of $0.15 \times 0.15 \times 0.15 \mathrm{~mm}$ was chosen and mounted on a Brucker Axis Spider CCD diffractometer, with $\omega / \varphi$ scan mode in the $2 \theta$ range of $3.30-25.01^{\circ}$. All measurements were performed at room temperature using graphite monochromatized Mo Ka radiation $(\lambda=0.71073 \AA)$. A total of 4740 reflections were collected(Table 1). The structure was solved by direct methods and refined using a full-matrix least square procedure on $F^{2}$ with SHELIXL-97[29]. Anisotropic displacement parameters for all non-hydrogen atoms and isotropic temperature factors for hydrogen atoms were introduced.

The structure and the unit cell of $\beta$-L-arabinoseis shown in Fig.1a.and Fig.1b. Selected bond lengths and bond angles are collected inTable 2.

\begin{tabular}{ll}
\multicolumn{1}{c}{ Table 1. Crystal data and structure refinement for $\beta$-L-arabinose } \\
\hline Empirical formula & C5 H10 O5 \\
\hline Crystal system, Space group & Orthogonal, P2(1)2(1)2(1) \\
Unit cell dimensions & $\mathrm{a}=4.8831(10) \mathrm{A} \quad \mathrm{b}=6.5149(13) \mathrm{A}$ \\
& $\mathrm{c}=19.440(4) \mathrm{A} \quad \alpha=\beta=\gamma=90 \mathrm{deg}$. \\
Z, Calculated density & $4,1.629 \mathrm{Mg} / \mathrm{m} 3$ \\
Absorption coefficient & $0.148 \mathrm{~mm}^{\wedge}-1$ \\
Theta range for data collection & 3.30 to $25.01 \mathrm{deg}$. \\
Limiting indices & $-5<=\mathrm{h}<=5,-7<=\mathrm{k}<=7,-23<=1<=23$ \\
Reflections collected / unique & $4740 / 1078[\mathrm{R}(\mathrm{int})=0.0273]$ \\
Completeness to theta $=27.45$ & $99.9 \%$ \\
Data / restraints / parameters & $1078 / 0 / 131$ \\
$\mathrm{~S}$ & 1.039 \\
Final R indices [I $>2$ sigma(I)] & $\mathrm{R} 1=0.0275, \mathrm{wR} 2=0.0528$ \\
$\mathrm{R}$ indices (all data) & $\mathrm{R} 1=0.0389, \mathrm{wR} 2=0.0558$ \\
Largest diff. peak and hole & 1.198 and $-0.371 \mathrm{e} . \mathrm{A}^{\wedge}-3$ \\
\hline
\end{tabular}

The unit cell of $\beta$-L-arabinose $(a=4.8331 \AA, b=6.5149 \AA, c=19.440 \AA, \alpha=\beta=\gamma=$ $90.00^{\circ}$ ) is accordance with to previous reports[30]. It belongs to $P 2_{1} 2_{1} 2_{1}$ space group, and the four molecules in the unit cell (Fig. 1b) are located at:
$\mathrm{M}(1): \mathrm{x}, \mathrm{y}, \mathrm{z}$,
$\mathrm{M}(2):-\mathrm{x}+1 / 2,-\mathrm{y}, \mathrm{z}+1 / 2$,
$M(3):-x, y+1 / 2,-z+1 / 2, \quad M(4): x+1 / 2,-y+1 / 2,-z$, 
Table 2. Bonds length $(\AA)$ and angle(deg) for L-arabinose

\begin{tabular}{llll}
\hline Bond & Length/angle & Bond & Length/angle \\
\hline $\mathrm{C}(1)-\mathrm{O}(5)$ & $1.424(2)$ & $\mathrm{C}(3)-\mathrm{O}(3)$ & $1.429(2)$ \\
$\mathrm{C}(1)-\mathrm{O}(1)$ & $1.399(2)$ & $\mathrm{C}(3)-\mathrm{C}(4)$ & $1.511(3)$ \\
$\mathrm{C}(1)-\mathrm{C}(2)$ & $1.512(2)$ & $\mathrm{C}(4)-\mathrm{O}(4)$ & $1.425(3)$ \\
$\mathrm{C}(2)-\mathrm{O}(2)$ & $1.431(2)$ & $\mathrm{C}(4)-\mathrm{C}(5)$ & $1.500(3)$ \\
$\mathrm{C}(2)-\mathrm{C}(3)$ & $1.510(3)$ & $\mathrm{C}(5)-\mathrm{O}(5)$ & $1.442(2)$ \\
$\mathrm{O}(5)-\mathrm{C}(1)-\mathrm{O}(1)$ & $112.16(16)$ & $\mathrm{O}(3)-\mathrm{C}(3)-\mathrm{C}(4)$ & $111.95(16)$ \\
$\mathrm{O}(1)-\mathrm{C}(1)-\mathrm{C}(2)$ & $108.15(16)$ & $\mathrm{C}(4)-\mathrm{C}(3)-\mathrm{C}(2)$ & $109.95(14)$ \\
$\mathrm{O}(5)-\mathrm{C}(1)-\mathrm{C}(2)$ & $109.66(14)$ & $\mathrm{O}(4)-\mathrm{C}(4)-\mathrm{C}(5)$ & $109.39(19)$ \\
$\mathrm{O}(2)-\mathrm{C}(2)-\mathrm{C}(3)$ & $111.84(14)$ & $\mathrm{O}(4)-\mathrm{C}(4)-\mathrm{C}(3)$ & $110.72(19)$ \\
$\mathrm{O}(2)-\mathrm{C}(2)-\mathrm{C}(1)$ & $107.64(15)$ & $\mathrm{C}(3)-\mathrm{C}(4)-\mathrm{C}(5)$ & $109.86(17)$ \\
$\mathrm{C}(3)-\mathrm{C}(2)-\mathrm{C}(1)$ & $110.20(16)$ & $\mathrm{O}(5)-\mathrm{C}(5)-\mathrm{C}(4)$ & $110.99(18)$ \\
$\mathrm{O}(3)-\mathrm{C}(3)-\mathrm{C}(2)$ & $109.50(16)$ & $\mathrm{C}(1)-\mathrm{O}(5)-\mathrm{C}(5)$ & $113.06(13)$ \\
\hline
\end{tabular}

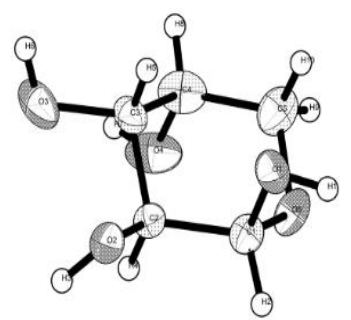

Figure 1. Molecular structure and the unit cell of $\beta$-L-arabinose

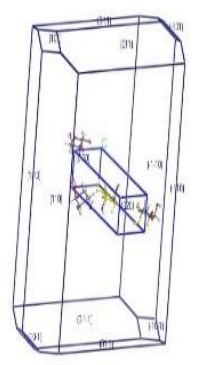

Figure 2. The morphology and growth faces of $\beta$-L-arabinose calculated by BFDH method

\section{Morphology Prediction by MS}

The crystal structure of L-arabinose was optimized by forcitemoduleswith "Fine" quality [31]. The simulation was conducted under such conditions: electronic charges were computed by "compass method", and both the summation methods with a quality of "medium" were set to "Ewald". Results were compared with the natural crystal obtained from aqueous solution by cooling crystallization.

\section{Results and Discussion}

\section{Morphology of $\beta$-L-arabinose Calculated by BFDH Method}

The crystal shape of L-arabinose by BFDH method is approximate rectangular parallelepiped, with an aspect ratio of 2.552(Fig. 2). Face $\{020\}$ is the largest facet and occupies $40.86 \%$ of the total area, followed by $33.68 \%$ of $\{110\}$, and $23.73 \%$ of $\{011\}$. Face $\{101\}$ is the smallest facet that accounts $1.71 \%$ of the total area.

The arrows in Fig. 2b represents the growth trends of varies faces based on the data obtained. Thearrowsdensityof the major crystal facet has no great difference.Among various growth face, $D_{020}$ is the smallest $\left(10.273 \times 10^{-10} \mathrm{~m}\right)$, followed by $D_{110}\left(16.14 \times 10^{-10} \mathrm{~m}\right)$, and $D_{011}\left(21.286 \times 10^{-10} \mathrm{~m}\right)$. This is because the $R_{020}$ is the smallest, followed by $R_{110}, R_{011}$ and $R_{101}$. The faster the growth rate is, the larger the distance 
from the center to face and the smaller face area. Among all the crystal facet, $\{101\}$ has the fastest growth rate while $\{020\}$ has the slowest. The faces with the growth rate faster than $R_{101}$ growth very fast and will disappear from crystal facets. The actual crystal shape obtained from experiment by cooling crystallization was shown in Fig.3.It is a little different from that calculated by BFDH (especially the aspect ratio), this is because the morphology calculated by BFDH is carry out in vacuum and it take no consider of the molecular energy, packing of L-arabinose atom. BFDH method also consider not the influence of solvent effect on morphology of L-arabinose.

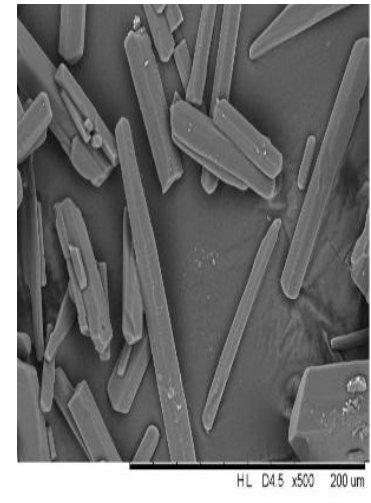

Figure 3. The morphology of $\beta$-L-arabinose obtained by experiment:a SEM, b morphology
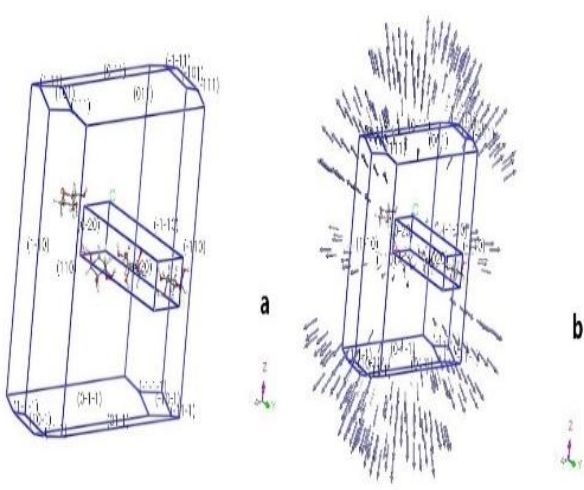

Figure 4. The morphology and growth faces of $\beta$-L-arabinose calculated by GM method

\section{Morphology of $\beta$-L-arabinose Calculated by GM}

The crystal shape of L-arabinose obtained by GM is consistent with that obtained by BFDH, with an aspect ratio of 3.165(Fig.4). With the multiplicity of 2 , the $\{020\}$ face has the largest percentage (48.68\%). Both $\{110\}$ and $\{011\}$ have the multiplicity of 4 , and occupy $25.39 \%$ and $24.32 \%$ of the total surface area, respectively. The area of $\{101\}$ is $1.57 \%$, closer to $1.71 \%$ of $\{101\}$ calculated by BFDH. Two new facet, $\{111\}$ and $\{11-1\}$ formed compared with BFDH, but its' influence on crystal habit was negligible as the area is relatively too small $(<0.01 \%)$. The $E_{a t t}$ of $\{020\},\{110\}$, $\{011\}$, and $\{101\}$ were $-35.786,-81.001,-90.044$, and $-110.587 \mathrm{~kJ} /\left(\mathrm{mol} \cdot \mathrm{unit} \mathrm{cell}^{-1}\right.$ ), respectively.

There exists an obvious difference between growth faces as calculated by GM (Fig.4b). The intensity of arrow of the $\{020\}$ face was significantly lower than both of the end faces, indicating $\{020\}$ face has the lowest growth rate and becomes the biggest crystal facet finally. The $R_{110}$ and $R_{011}$ is larger than $R_{020}$, and becomes the end facet of the crystal. The $d_{h k l}$ of $\{020\},\{110\},\{011\}$, and $\{101\}$ were $9.595 \times 10^{-10}$, $5.979 \times 10^{-10}, 4.644 \times 10^{-10}$, and $3.809 \times 10^{-10}$, respectively. This is consistent with the theory that the larger the $d_{h k l}$ is, the little the $R_{h k l}$ and the larger $M I$ will be. The crystal morphology calculated by GM method is nearly cuboid and is consistent with the crystal shape obtained in the aqueous crystallization.

\section{Morphology of $\beta$-L-arabinose Calculated by EM}

The crystal shape obtained by EM is approximately spherical, with the aspect ratio of 1.643. Face $\{020\}$ and $\{021\}$ is the largest face of the crystal( $26.09 \%$ and $22.21 \%$ of 
the total area, respectively)(Fig.5). The other 50 pairs of faces accounted $51.7 \%$ of the total surface area. Out of all the possible surface configurations, the one with the lowest surface energy dominates the habit facet. In which $\{020\}$ face with the multiplicity of 2 has the lowest surface energy $(0.2979 \mathrm{~kJ} / \mathrm{mol})$, indicating $\{020\}$ face has the lowest growth rate and dominate the crystal facet finally.

The arrows density in $\{020\}$ and $\{021\}$ face slightly below the density of end side faces, and the intensity of end side faces was approximately the same, indicating the growth rate of $\{020\}$ and $\{021\}$ faces were the slowest (Fig. 5b). The crystal shape obtained by EM is nearly spherical, which is not consistent with the reality one, because the morphology obtained by EM is simulated at Zero $\mathrm{K}$, while in realityit is obtained from aqueous solution at a temperature higher than room temperature.
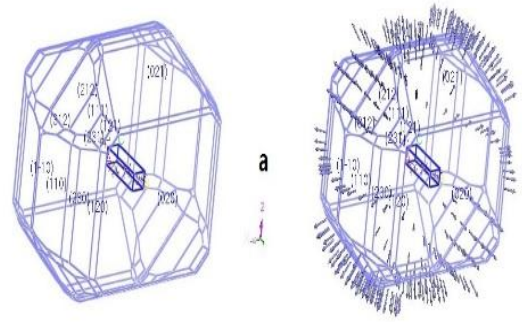

Figure 5. The morphology and growth faces of $\beta$-L-arabinose by EM method

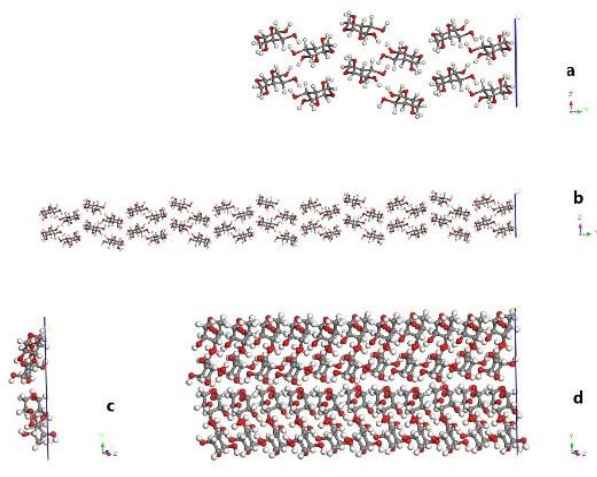

Figure 6. Projection of the facet: a : $\{020\}$ simulatedcalculated by GM, b: $\{020\}$ by EM, $c:\{101\}$ by GM, and $d:\{101\}$ by EM

Summary of the morphology obtained by Material Studio was shown in Table 3.With the evolution of algorithms from simple to complex, the number of unique facet increased from 4 to 6 then to 52. What remain the same was the largest facet $\{020\}$. Details of face $\{020\}$ were shown in Table 4 .

Table 3. Summary of the morphology obtained by Material Studio

\begin{tabular}{cccccccc}
\hline Method & $\begin{array}{c}\text { Aspect } \\
\text { ratio }\end{array}$ & $\begin{array}{c}\text { surface / } \\
\text { volume ratio }\end{array}$ & $\begin{array}{c}\text { Total } \\
\text { facets }\end{array}$ & $\begin{array}{c}\text { Unique } \\
\text { facets }\end{array}$ & $\begin{array}{c}\text { Largest } \\
\text { Facet }\end{array}$ & $\begin{array}{c}\text { Second } \\
\text { largest } \\
\text { Facet }\end{array}$ & $\begin{array}{c}\text { Crystal } \\
\text { Shape }\end{array}$ \\
\hline BFDH & 2.552 & 1.214 & 14 & 4 & $\{020\}$ & $\{110\}$ & $\begin{array}{c}\text { rectangular } \\
\text { parallelepiped } \\
\text { Growth }\end{array}$ \\
\hline Equilibrium & 1.165 & 1.268 & 22 & 6 & $\{020\}$ & $\{110\}$ & cuboid \\
\hline
\end{tabular}

Table 4. Some Properties of facet $\{020\}$ calculated by different method

\begin{tabular}{|c|c|c|c|c|c|c|c|}
\hline Method & $\mathrm{d}_{\mathrm{hkl}}$ & $\begin{array}{c}\mathrm{E}_{\text {att }} / \mathrm{E}_{\text {surf }}{ }^{*} \\
\text { (Total) }\end{array}$ & $\begin{array}{c}\mathrm{E}_{\text {att }} / \mathrm{E}_{\text {surf }} \\
(\mathrm{vdW})\end{array}$ & $\begin{array}{l}E_{\text {att }} / E_{\text {surf }} \\
\text { (Electro) }\end{array}$ & Distance & $\begin{array}{c}\text { Total } \\
\text { facet area }\end{array}$ & $\begin{array}{c}\% \text { Total } \\
\text { area }\end{array}$ \\
\hline BFDH & 9.733 & - & - & - & 10.2737 & $\begin{array}{l}2.105 \mathrm{e} \\
+3\end{array}$ & 40.861 \\
\hline Growth & 9.595 & -35.786 & -15.374 & -20.4124 & 35.786 & $4.448 \mathrm{e}+4$ & 48.683 \\
\hline Equilibrium & 9.595 & 0.297 & 0.1281 & 0.1697 & 297.94 & $5.701 e+5$ & 26.098 \\
\hline
\end{tabular}

The unit of energy is $\mathrm{KJ} / \mathrm{mol}$ 
The $d_{h k l}$ calculated by those three methods is similar to each other. However, the distance and total facet area of facet $\{020\}$ increased significantly from $2.105 \mathrm{e}+3$ of $\mathrm{BFDH}$ to $4.447 \mathrm{e}+4$ of GM method, then to $5.7 \mathrm{e}+5$ of EM method, which means that the size of unit cell is $\mathrm{EM}>\mathrm{GM}>\mathrm{BFDH}$. Why this happened?The projection of facet $\{020\}$ calculated by GM and EMcan explain thephenomenon(Figs.6a and 6b).

The thickness of the $\{020\}$ facet deduced by GM is 6 molecular(Fig.6a), while it is 22 molecular by EM(Fig.6b). The thickness calculated by GM is far less than that deduced by EM, this is the reason why the distance and total facet area changed. We also found that there exists no active oxygen atom of $\{020\}$ facet, which means that it can't form hydrogen bonds with the $\mathrm{H}$ atoms of surfactant(Figs.6a and 6b). So, surfactant or tailor-made additives can't be adsorbed on the crystal surface $\{020\}$. However, surfactant or tailor-made additives may form hydrogen bonds with the fast growing facet such as $\{011\}$ or $\{101\}$. As seen inFigs. 6c and 6d, there exist at least one hydroxyl group outside of the $\{101\}$ face, and some hydrogen atom of hydroxyl groups on the face. The hydrogen atoms and hydroxyl on or outside of the face can form intermolecular hydrogen bond with tailor-made additives[32, 33], which leads to occupy of crystal surface by tailor-made additives or solvent [2]. By occupying the crystal surface, the additives can delay or prohibit the solute to dock on crystal surface thus lead to the reduction of growth rate, meanwhile, the adhesion of additives on crystal surface will increase the standing layer thickness and bloke the mass transfer of solute from mother liquor to crystal surface, and ultimately achieve the purpose of controlling crystal habit.

\section{Conclusion}

(1)The morphology of $\beta$-L-arabinose calculated by BFDH, GM and EM method is approximate rectangular parallelepiped, nearly cuboid and nearly spherical, respectively. The shape simulated by GM is consistent with the experimental crystal obtained by cooling crystallization. The $\{020\}$ is the largest among all the facets calculated, which accounts $40.86 \%, 48.68 \%$ and $26.10 \%$, respectively.

(2) Surfactant or tailor-made additives can't change the growth rate of $R_{020}$ as there exists no active hydroxyl group or hydrogen atom on $\{020\}$ facet. However, a hydroxyl group is exposed outside of the $\{101\}$ face, together with some hydrogen atom of hydroxyl groups, which can react with tailor-made additives or solvent and change the growth rate. Therefore, the purpose of controlling crystal habit is accomplished by the modifying standing layer thickness and the relative growth rate.

\section{Acknowledgement}

This research was financially supported by the Gunagdong Science Foundation 2013B060600001, 2015A010107008, and Guangdong academic of science project 2016GDASPT-0108. 


\section{References}

[1] Gadewar, S.B. and M.F. Doherty. Journal Of Crystal Growth, 2004. 267(2): p. 239-250.

[2] Zhang, C., et al. Crystal Growth \& Design, 2013. 13(1): p. 282-290.

[3] Bravais, A. Etudes Cristallographiques. 1913, Paris: Academie des Sciences.

[4] Friedel, M.G. Etudes Sur la loi de Bravais. Bull. Soc. Franc.Miner, 1907(30): p. 326-332.

[5] Donnay, J. and D. Harker. Am. Mineral, 1937. 5(22): p. 446-467.

[6] Hartman, P. and W. Perdok.ActaCrystallogr., 1955. 1(8): p. 49-52.

[7] Hartman, P. and W. Perdok. ActaCrystallogr., 1955. 9(8): p. 521-524.

[8] Hartman, P. and W. Perdok. ActaCrystallogr., 1955. 9(8): p. 525-529.

[9] Bennema, P., et al. Crystal Growth \& Design, 2004. 4(5): p. 905-913.

[10] Massimino, F., et al. Crystal research And Technology, 2011. 46(8): p. 789-794.

[11] Berkovitch-Yellin, Z., J. van Mil and L. Addadi. Journal of the American Chemical Society, 1985. 11(107): p. 3111-3122.

[12] Docherty, R., et al. Journal of Physics D (Applied Physics), 1991(24): p. 89-99.

[13] Schmidt, C. and J. Ulrich. Journal Of Crystal Growth, 2012. 353(1): p. 168-173.

[14] Seri, K., et al. Metabolism, 1996. 45(11): p. 1368-1374.

[15] Shibanuma, K., Y. Degawa and K. Houda. European Journal of Nutrition, 2011. 50(6): p. 447-453.

[16] Inger, K., et al. American Journal of Clinical Nutrition, 2011. 94(2): p. 472-478.

[17] Liu, X., et al. Journal of hygiene research, 2013. 42(2): p. 295--297.

[18] CHOI, Y.S., K.C. CHUNG and J. DU, Process for preparation of 2-fluoro-5-methyl-beta-L-arabinofuranosyluridine IN186807-B. 2014.

[19] Choung, B.S., et al. Gut And Liver, 2012. 6(4): p. 486-492.

[20] Jia, J., et al. Hepatology International, 2014. 8(1): p. 72-82.

[21] Li, X., et al. Hepatology Research, 2013. 44(2): p. 25-29.

[22] Loessner, H., et al. Cellular microbiology, 2007. 9(6): p. 1529--1537.

[23] Jeong, J.H., et al. PLoS One, 2014. 9(1): p. e80050.

[24] Kaluzhny, D.N., et al. ChemMedChem, 2009. 4(10): p. 1641--1648.

[25] Yamauchi, S. and Y. Kinoshita. Bioscience Biotechnology And Biochemistry, 2001. 65(7): p. 1669-1672.

[26] EL-Farargy, A.F. and A.A. Ghonium. ARKIVOC, 2008. 13: p. 278--285.

[27] Becker, J. and E. Boles. Applied And Environmental Microbiology, 2003. 69(7): 
p. $4144-4150$.

[28] Jeon, Y.J., M.B. Park and I.H. Kim. Bioprocess AndBiosystems Engineering, 2010. 33(1SI): p. 87-95.

[29] Sheldrick, G.M., SHELX-97, Program for the solution and refinement of crystal structures. 1997, Germany: University of Göttingen.

[30] TAKAGI, S. and G.A. JEFFREY. ActacrystallogrA, 1977(b33): p. 3033-3040.

[31] Hu, X., et al. Chemical Engineering \& Technology, 2013. 36(8): p. 1355-1358.

[32] Clydesdale, G., et al. Crystal Growth \& Design, 2005. 5(6): p. 2154-2163.

[33] Tian, G.R. and S.X. Sun CrystalResearchAnd Technology, 2011. 46(4): p. 389-392. 